\title{
Mental Health Status Among the Staff of Harm Reduction Centers
}

\author{
Majid Rezazade ${ }^{1, *} ;$ Zeynab Lashani $^{2} ;$ Khodabakhsh Ahmadi $^{3}$ \\ ${ }^{1}$ AIDS Prevention and Control Committee, Welfare Organization State, Tehran, IR Iran \\ AIDS Prevention and Control Committee, Welfare Organization State,
${ }_{2}^{2}$ Department of Human Sciences, Shahed University, Tehran, IR Iran \\ 3 Department of Human Sciences, Shahed University, Tehran, IR Iran
Behavioral Sciences Research Center, Baqiyatallah University of Medical Sciences, Tehran, IR Iran \\ ${ }^{*}$ Corresponding author: Majid Rezazade, AIDS Prevention and Control Committee, Welfare Organization State, P.O.Box: 19395-5487, Tehran, IR Iran. Tel: +98-2155951581, Fax: +98- \\ 2151212404, E-mail:dr_ma_rezazade@yahoo.com \\ Received: May 19, 2013; Revised: December 14, 2013; Accepted: January 27, 2014
}

\begin{abstract}
Background: Creating a supportive environment encourages charity services to help risk groups and individuals which has magnificent impacts on reducing their harm.

Objectives: According to this plan, the purpose of this study was to investigate the mental health status in the staff of harm reduction centers.

Materials and Methods: The clustered sample of this comparative study consisted of 49 staff of harm reduction centers. The study was supported by the United Nations Development Program in Tehran, Iran. The participants completed GHQ-28 and DASS-21 questionnaires along with sociologic forms and the results were evaluated by descriptive statistics indexes and independent sample t-test.

Results: One-hundred percent of the participants in this study showed the symptoms of psychological disorders, and approximately 16 percent suffered from moderate to high degree of anxiety, depression and stress. The level of anxiety $(\mathrm{P}<0.04)$ and stress $(\mathrm{P}<0.01)$ in the younger staff (less than 40 years) was significantly higher than older staff (more than 40 years old). In addition, somatic symptoms $(\mathrm{P}<$ $0.05)$ and social withdrawal $(\mathrm{P}<0.01)$ were significantly higher in women than men.

Conclusions: Accordingly, major mental disorders in the staff of harm reduction centers, especially women and younger people need to be considered more than before.
\end{abstract}

Keywords:Mental Health; Harm Reduction; Anxiety; Depression; Substance-Related Disorders

\section{Background}

In 2004, the World Health Organization (WHO) suggested to perform developed interventions for harm reduction to prevent HIV outbreak in all countries. One of the harm reduction programs in Iran is run jointly by AIDS Prevention and Control Committee, Welfare Organization State, Behavioral Sciences Research Center, Baqiyatallah University of Medical Sciences and backed by the financial support of global fund to fight aids, tuberculosis and malaria (GFATM) and United Nations Development Programme (UNDP). In these centers HIV/AIDS prevention education is provided for people with high risk behaviors such as intravenous drug use or unprotected sex. Harm reduction among high risk behavior people with HIV/AIDS is one of the preventive strategies to reduce unhealthy impacts on the society and economy. Harm reduction interventions include educating the people with high risk behavior and providing them with syringes, condoms, and alternative treatments for opioids and so on $(1,2)$. Regarding disorders and problems of high risk behavior people (3-5) these interventions are of great importance and are applicable in many situations (6).
Effective approaches to reduce harms are as follows:

- Promoting health actions through applying the general policies of health promotion and AIDS prevention.

- Creating a supportive environment for people at risk and/ or with high risk behaviors.

- Familiarizing health centers with AIDS prevention services and principles.

- Contributing actively in the developing and strengthening personal skills in decision making.

- Communicating with others, adopting assertive decision and changing high risk behaviors (7).

Therefore, creating a supportive environment ( for the people at risk, and/or with the high risk behavior) to build trust and provide services have a significant effect on HIV prevalence reduction (7); a significant part of this important task is the responsibility of the staff of harm reduction centers.

But, one of the main problems of addicts is communicating with non-addicts who live with them (8), so dealing with high risk people may cause problems such as unsustainability in the staff of harm reduction centers. Since mental health is one of the variables which improves jobs sustainability (9) and associates with internal power resources, it can increase the capability of the staff, despite unfavorable

Implication for health policy makers/practice/research/medical education:

This study investigated the mental health status among the staff of Tehran Harm Reduction Centers. As we know, it is the first research study about this subject in Iran.

Copyright (C) 2014, Zahedan University of Medical Sciences; Published by Kowsar Corp. This is an open-access article distributed under the terms of the Creative Commons Attribution License, which permits unrestricted use, distribution, and reproduction in any medium, provided the original work is properly cited. 
conditions and negative events (10). Stresses, unsuitable living conditions, social exclusions and employment disparities are associated with mental health disorders. Besides, stresses and coping skills of individuals are among important factors associated with mental health problems (11).

Since mental health is a significant factor in preventing social problems such as addiction to alcohol, drugs, and gambling (12), the current study has investigated the mental health of staff of Tehran harm reduction centers as one of the effective variables of harm reduction. Thereby, the question is: "How well is the mental health status of staff of the harm reduction center?"

\section{Objectives}

According to this plan, the purpose of this study was to investigate the mental health status in the staff of harm reduction centers.

\section{Materials and Methods}

In the current comparative study, the subjects were the staff of harm reduction centers of UNDP Global Fund project in Iran selected by cluster sampling method: 49 subjects including 34 (69.4\%) men and 15 (30.6\%) women. The centers were as follows: Shosh, Fallah, Rey-Nafarabad, Rey-Sarcheshme, Khaniabad, Valiasr Town, Jannatabad, Ostad Moein and Sadeghieh.

Data collection tools were general health questionnaire (GHQ-28), and depression, anxiety and stress scale (DASS-21). This questionnaire was designed by Goldberg and Hillier in 1979 and is the most widely used tool for general screening in mental health which included 28 questions with Likert scoring as $\mathrm{A}=0, \mathrm{~B}=1, \mathrm{C}=2$, and $\mathrm{D}=3$ (13). The validity of this questionnaire is reported $95 \%$ by Goldberg and Williams (14) and has been widely used as a major screening method in more than 30 countries such as Brazil, Chili, Germany, France, Greece, India, Italy and Japan (14).

Gibbons et al. identified four factors including physical symptoms, anxiety, insomnia, social functioning disorder, and depression among a student population sample (15). The highest correlation was observed among physical symptoms, anxiety and insomnia. Reliability of the questionnaire was measured by test-retest with 0.74 reliability coefficient, 6.7 cut-off point, 0.88 test accuracy, and 84.2 specificity (15).

In the current study, according to the Fathiashtiani and Dastani (16) and Yaghoubi (17), the cut-off point was considered as 7 points for subscales, and 23 points for total scale which indicates the level of disorder. The scale of depression, anxiety and stress (DASS-21) was designed by Lovibond and Lovibond and is a combination of three self-assessment subscales to measure the negative emotional state of depression, anxiety and stress (18). Each subscale has 7 items.

Validity and reliability of this scale have been evaluated in Iranian population by Asghari Moghaddam et al. (19). They confirmed the exploratory factor analysis of three-factor structure of DASS, and also the reliability of its scales through evaluating internal consistency and retest indexes. Generally, the validity and reliability of the tests were satisfactory.

The correlation between DASS depression subscale and Beck's depression scale was 0.69, and between DASS depression subscale and anxiety subscale, four-system anxiety, was 0.62. In factor analysis results, the three-factor model (depression, anxiety and stress) was able to explain the data better than other models. Generally, threefactor model explained $54.04 \%$ of variance.

In the current study, according to Fathiashtiani and Dastani DASS-21 cut-off points are higher than 10.5 for depression subscale, higher than 7.5 for anxiety subscale, and higher than 13 for stress subscale which showed the higher level of the disorder (16).

The results of statistical descriptive tests and t test in independent groups were evaluated by statistical package for the social science version 18 .

\section{Results}

Descriptive results from demographic features indicated that $49 \%$ of subjects were single, $46.9 \%$ married, and $2 \%$ divorced. Also, $12.5 \%$ had a bachelor or higher degrees, 8.2\% associate degree, 26.5\% high school diploma and 38.13\% lower degrees (Table 1).

Analyzing descriptive indexes of depression, anxiety and stress (DASS-21) scores of staff of harm reduction centers showed that $16 \%$ suffered from severe and higher level of anxiety, 16.3\% had severe and higher level of depression, and $16.3 \%$ with severe and higher level of stress. Also, according to the GHQ questionnaire, $100 \%$ of the subjects suffered from some symptoms of psychological disorders, such as physical disorders, anxiety, socio-occupational disorders and depression (Table 2 ).

\begin{tabular}{ll}
\hline \multicolumn{1}{l}{ Table1. Demographic Features of the Staff of Harm Reduction Centers } \\
\hline Variable & No. $(\%)$ \\
\hline Gender & \\
\hline Men & $34(69.4)$ \\
\hline Women & $15(30.6)$ \\
\hline Marital status & $24(49)$ \\
\hline Single & $23(46.9)$ \\
\hline Married & $1(2)$ \\
\hline Divorced & \\
\hline Education & $2(1.4)$ \\
\hline Illiterate & $3(6.1)$ \\
\hline Elementary & $8(16.3)$ \\
\hline Guidance school & $7(14.3)$ \\
\hline High school & $13(26.5)$ \\
\hline High school Diploma & $4(8.2)$ \\
\hline Associate degree & $12(24.5)$ \\
\hline Bachelor and higher & \\
\hline
\end{tabular}


Comparing the level of anxiety, depression, stress and general health among the staff of harm reduction centers, according to the demographic features showed that the level of anxiety $(\mathrm{P}<0.04)$ and stress $(P<0.01)$ among the staff younger than 40 were sig- nificantly higher than those of over 40 . Level of physical disorders and insomnia $(\mathrm{P}<0.05)$, and socio-occupational disorders $(\mathrm{P}<0.01)$ in women staff of harm reduction centers were significantly higher than men (Table 3).

Table 2. Descriptive Indexes of Anxiety, Depression and Stress in the Staff of Harm Reduction Centers

\begin{tabular}{lllll}
\hline & Average & Standard Deviation & Cut-off Point & People With Disorders, No. (\%) \\
\hline Anxiety (DASS) & 3.20 & 3.84 & 7.5 & $8(16)$ \\
Depression(DASS) & 6.33 & 4.27 & 10.5 & $8(16.3)$ \\
Stress (DASS) & 5.34 & 5.33 & 13 & $8(16.3)$ \\
$\begin{array}{l}\text { Physical disorder and insomnia } \\
\text { (GHQ) }\end{array}$ & 11.03 & 3.63 & 7 & $49(100)$ \\
Anxiety disorder (GHQ) & & & 7 & $49(100)$ \\
Socio-occupational Disorder(GHQ) & 12.75 & 3.13 & 7 & $49(100)$ \\
\hline $\begin{array}{l}\text { Severe depression (GHQ) } \\
\text { General health disorder (GHQ) }\end{array}$ & 9.11 & 3.71 & 7 & $49(100)$ \\
\hline
\end{tabular}

Table 3. Comparing Mental Health Based on Independent $t$-test Groups Variable

\begin{tabular}{|c|c|c|c|c|c|c|c|}
\hline & \multirow[t]{2}{*}{ SD Average } & \multirow{2}{*}{$\begin{array}{l}\text { Standard } \\
\text { Error }\end{array}$} & \multirow[t]{2}{*}{$t$} & \multirow{2}{*}{$\begin{array}{l}\text { Degree of } \\
\text { Freedom }\end{array}$} & \multirow{2}{*}{$\begin{array}{l}\text { Level of Sig- } \\
\text { nificance }\end{array}$} & \multicolumn{2}{|c|}{ Level of confidence $95 \%$} \\
\hline & & & & & & Min & Max \\
\hline \multicolumn{8}{|c|}{ Anxiety (DASS) } \\
\hline Gender & & 1.20 & -0.58 & 47 & 0.56 & -3.11 & 1.711 \\
\hline Men & $2.99(3.41)$ & & & & & & \\
\hline Women & $3.69(4.78)$ & & & & & & \\
\hline Education & & 1.12 & 0.13 & 47 & 0.75 & -2.11 & 2.42 \\
\hline Lower than diploma & $3.29(3.57)$ & & & & & & \\
\hline Higher than diploma & $3.14(4.08)$ & & & & & & \\
\hline Age & & 1.24 & 2.06 & 36.45 & 0.04 & 0.04 & 4.41 \\
\hline Less than 40 years & $4.19(4.65)$ & & & & & & \\
\hline Over 40 years & $1.95(2.18)$ & & & & & & \\
\hline \multicolumn{8}{|c|}{ Depression (DASS) } \\
\hline Gender & & 1.33 & -0.07 & 47 & 0.94 & -2.79 & 2.59 \\
\hline Men & $6.30(4.42)$ & & & & & & \\
\hline Women & $6.39(4.07)$ & & & & & & \\
\hline Education & & 1.23 & 1.38 & 47 & 0.55 & -0.77 & 4.17 \\
\hline Lower than diploma & $7.33(4.47)$ & & & & & & \\
\hline Higher than diploma & $5.63(3.23)$ & & & & & & \\
\hline Age & & 1.22 & 1.40 & 38.55 & 0.16 & -0.75 & 4.19 \\
\hline Less than 40 years & $7.08(4.59)$ & & & & & & \\
\hline Over 40 years & $5.36(3.23)$ & & & & & & \\
\hline \multicolumn{8}{|c|}{ Stress (DASS) } \\
\hline Gender & & 1.66 & -0.27 & 47 & 0.78 & -3.80 & 2.90 \\
\hline Men & $5.20(5.23)$ & & & & & & \\
\hline Women & $5.66(5.70)$ & & & & & & \\
\hline Education & & 1.54 & 0.98 & 47 & 0.47 & -1.58 & 4.64 \\
\hline
\end{tabular}


Rezazade Met al.

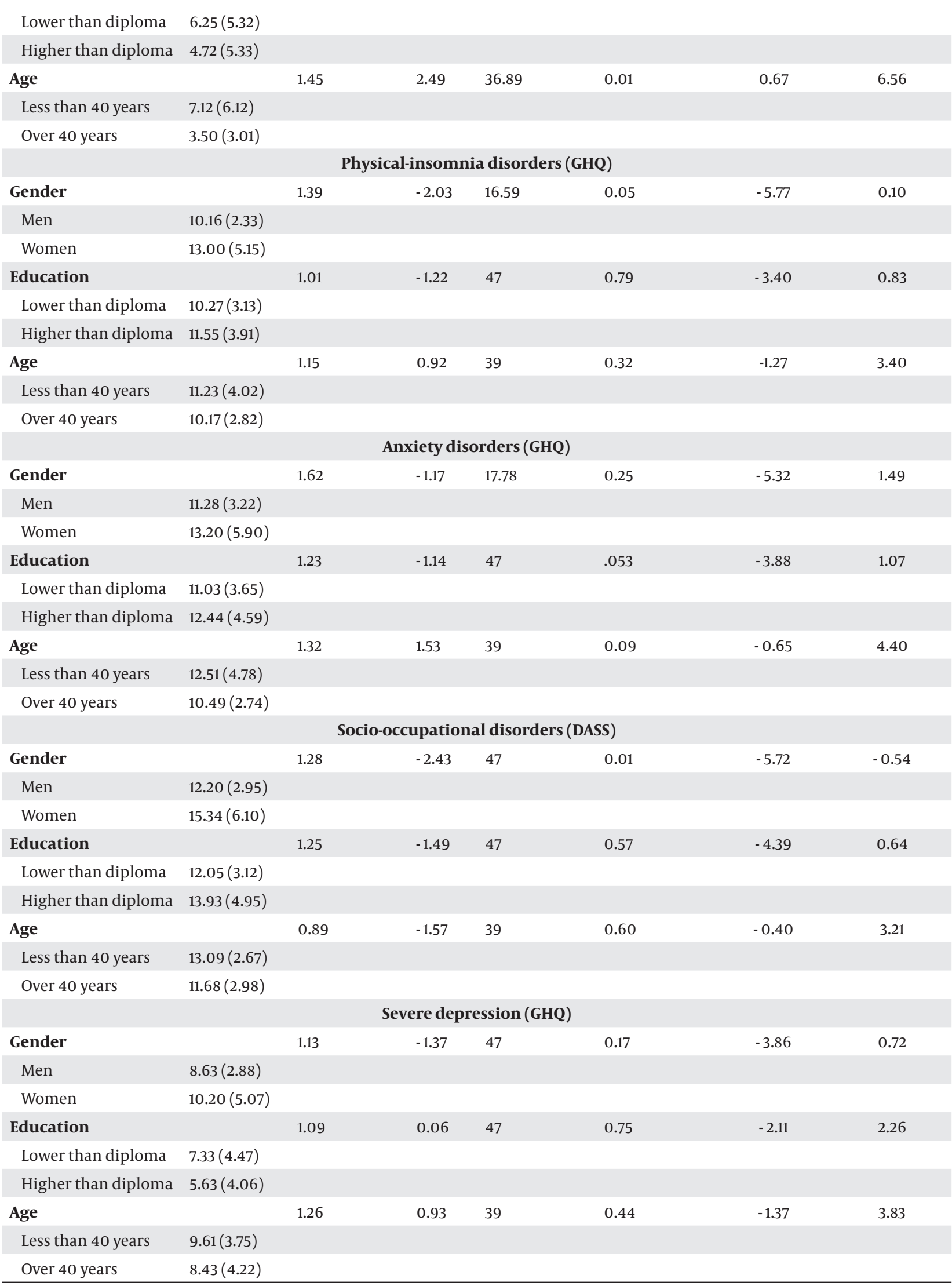




\section{Discussion}

Investigation on mental health status of the staff of Tehran harm reduction centers showed that all of them suffered from mental health disorders, and almost $16 \%$ experienced serious levels of depression, anxiety and stress. Also, the levels of physical and socio-occupational disorders in women were significantly higher than fellow men. Besides, the results of the present study showed that the levels of anxiety and stress among staff younger than 40 years old were significantly higher than staff over 40 years old.

According to the 23 cut-off point (17) and Fathiashtiani et al. $100 \%$ of staff of harm reduction centers suffered from medium to high levels of disorders, and socio-occupational functioning disorder has the highest prevalence (65.1\%) (16). According to Sahebi (20), the prevalence of mental disorders among nurses is high. But, comparing the results of the present study and those of Sadeghi et al. which was performed on hospital nurses -investigated physical disorders, anxiety, socio-occupational functioning and depression- the average score of the current study was three times higher than that of Sadeghi's (21). Also, the staff of harm reduction centers had worse mental disorder than that of the staff of Behesht Zahra (S) organization (almost four times higher, according to the GHQ-28 questionnaire). In addition, participants of this study showed more mental disorders than student universities $(22,23)$. These findings indicated the need for considerable care and attention from responsible authorities (24).

In the current study, mental health status of women staff was worse than that of fellow men. Asad Zandi et al. reported that psychological problems of women staff were more severe than those of men staff; a finding that is consistent with our present study (25). Regarding the causes of these problems, social effects of women's attending the harm reduction centers should be noted. In this regard, Salehi et al. also showed that, among the people who referred to the facilities of the two different centers, "Medical Science University Headquarters" and "Education Department", there is a significant difference between the mental health status of these two departments' women staff(26).

In this study, women showed more physical-insomnia and socio-occupational disorders. Mohammadian et al. (27) in their similar study showed that older and educated subjects had suffered more of these two mental health disorders. According to the current study, aging is one of the important factors affecting human mental health. Also, results of the studies by Pollack et al.(28) and Seyedan et al. (29) showed the higher level of anxiety and stress in the staff younger than 40 which is compatible with the results of the present study. According to the Shabani et al. (30) promotion is associated with job satisfaction.

This study showed that the staff of harm reduction cen- ters suffered from considerable psychological problems. Accordingly, it seems reasonable that taking actions is necessary to improve the level of mental health in their staff. Thereby, the status of mental health in the staff of harm reduction centers (21), was significantly worse than that of nurses and staff of the Behesht Zahra (S) organization (24). The reason can lie in the relation between nonaddicts and addicts that may leave destructive effects on non-addicts (8). This is more obvious in significantly lower mental health status of women staff compare to the fellow men.

Mental health differences between men and women staff of harm reduction centers are compatible with the findings of the previous researches who studied this subject from theoretical aspect, or in other words, socio-occupational disorders. Thus, female nurses suffer from mental health disorders more than men (25), and the similar results were found in the school students by Goodarzi and Roodbali (31). Also from practical aspect, and according to the cultural and religious conditions of the population under study, the presence of women in harm reduction centers may cause more problems for women staff regarding socio-occupational situations.

Hence, it is necessary to consider more protective strategies for women staff in harm reduction centers, and preferably choose men for such jobs. Finally, Garousifarshi and Mani (32) showed that day shift staff suffered more from physical disorders and social problems than night shift workers. Finally, it may cause some differences among staff of harm reduction centers, and can be a subject for further researches.

\section{Acknowledgements}

Authors wish to thank the Harm Reduction Centers, Welfare Organization, AIDS Committee in Behavioral Science of Research Centers and all the staff participated in the study.

\section{Authors' contributions}

Study concept and design: Dr. Ahmadi, Lashani \& Dr. Rezazade. Analysis and interpretation of data: Zeynab Lashani and Dr. Khodabakhsh Ahmadi. Drafting the manuscript: Lashani, Dr. Ahmadi and Dr. Rezazade. Critical revision of the manuscript: Dr. Rezazade and Dr. Ahmadi. Statistical analysis: Lashan.

\section{Financial Disclosure}

The authors declared no conflict of interest.

\section{Funding/Support}

This study was supported in part by grant from the United Nations Development Programme (UNDP) and AIDS Prevention and Control Committee, Welfare Organization State, Tehran, IR Iran \& the Behavioral Sciences 
Research Center, Baqiyatallah University of Medical Sciences, Tehran, IR Iran.

\section{References}

1. Burrows , Starting D. Managing needles and syringes programs: a guide for Central and Eastern Europe/Newly Independent States. New York, International Harm Reduction Development/Open Society Institutes. 2000.

2. WorldHealthOrganisation. Biregional Strategy for Harm Reduction 2005-2009. HIV and Injecting Drug Use, 2005-2009. Geneva; 2009.

3. Ahmadlou M, Ahmadi K, Rezazade M, Azad-Marzabadi E. Global organization of functional brain connectivity in methamphetamine abusers. Clin Neurophysiol. 2013;124(6):1122-31.

4. Ahmadi K, Rezazade M, Akhavi Z, Zangane MA, Mooudifarid H. Familiar Specifications of People with Sexual High Risk Behaviors. Forth AIDS Seminar. Tehran, IR. 2012a.

5. Ahmadi K, Rezazade M, Nafarie M, Moazen B, Yarmohmmadi Vasel M, Assari S. Unprotected sex with injecting drug users among Iranian female sex workers: unhide HIV risk study. AIDS Res Treat. 2012;2012:651070.

6. Rezazade M, Ahmadi K, Nafarie M, Sedghijalal H. Efficacy of the Peer Educator Method in Decreasing AIDS High Risk Behavior. Third Seminar of AIDS. Tehran, IR. 2010.

7. Rezazade M, Mahzari K, Arezomandi M, Ahmadi K. AIDS Prohibition Education to High Risk Behavior People by Peer Educator Method.Tehran: Specialized Media Pub; 2009.

8. CAS.A National Survey of Canadians' Use of Alcohol and Other DrugsPrevalence of Use and Related Harms. Health Canada; 2005.

9. Hunter AE. Delving deeper into the commitment process: Preemployment factors, initial-entry commitment, and turnover. The George Washington University; 2009.

10. Jacelon CS. The trait and process of resilience. $J$ Adv Nurs 1997;25(1):123-9.

11. Milanifar B. Mental Disorders Screening: Situation of Tests and Cut-off Scoring Method and Validity Authenticating. Season J Mental Health. 1999;1(1):39-51.

12. Okasaka Y, Morita N, Nakatani Y, Fujisawa K. Correlation between addictive behaviors and mental health in university students. Psychiatry Clin Neurosci. 2008;62(1):84-92.

13. Goldberg DP, Hillier VF. A scaled version of the General Health Questionnaire. Psychol Med. 1979;9(1):139-45.

14. Goldberg DP, Williams P. A user's guide to the General Health Questionnaire. Nfer-Nelson; 1988.

15. Gibbons P, de Arévalo HF, Mónico M. Assessment of the factor structure reliability of the 28 item version of the general Health Questionnaire (GHQ-28) in El Salvador. Int J Clin Health Psychol. 2004;4(2):389-98.

16. Fathiashtiani A, Dastani M. Mental Health and Psychological Charac- teristics Evaluating Tests. First ed. Tehran, Iran: Besaat; 2009. p 312.

17. Yaghoubi H. Screening of mental disorders: Tests and way of scoring and validation. J Mental Health. 2008;1(1):39-51.

18. Lovibond PF, Lovibond SH. The structure of negative emotional states: comparison of the Depression Anxiety Stress Scales (DASS) with the Beck Depression and Anxiety Inventories. Behav Res Ther. 1995;33(3):335-43.

19. Asghari A, Saed F, Dibajnia P. Psychometric properties of the Depression Anxiety Stress Scales-21 (DASS-21) in a non-clinical Iranian sample. Int J Psychol. 2008;2:82-102.

20. Sahebi L, Ayatollahi MT. [The survey of mental health in hospital staff in Shiraz].J Ofogh-e-Danesh. 2006;12(4):26-33.

21. Sadeghi A, Rahmani B, Kiai MZ, Ahmadpour M, Mohammadi R, Nabavi SH. Mental health situation of shahidrajai therapeuticeducational center' staff in Qazvin. North Korasan Med Sci Univ J. 2010;2(4):33-8.

22. IrajiNaghandar R, Pourjafarian M. Mental Health in University Students. Contemporary Psychol. 2011;5:119-21.

23. BakhshiPour Roudsari A, MohammadPour V, Gholamzadeh M Esmaili Anamagh B. The Prediction of mental health, marital adjustment and passion to relationship in base of Mindfulness. Contemporary Psychol. 2011;5:142-3.

24. Haghshenas H, Rezaeean M, Sanei B, Houshmand AS. Mental Health and Job Satisfaction of Behesht Zahra (S) Organization Staff. Hakim Res J. 2003;6(4):57-64.

25. Asad Zandi M, Sayari R, Ebadi A, Sanainasab H. Abundance of depression, anxiety and stress in militant Nurses. J Mil Med. 2011;13(2):103-8.

26. Salehi B, Seif K, Jamilian HR, Gheble F. Comparison of mental health status between employed women in Arak University of Medical Sciences and official staffs of Education office, Arak, 2008. Res Sci J Med Sci Univ Arak. 2009;12(3):77-84.

27. Mohammadian M, Dadfar M, Bolhari J, Karimi Kesami E. Screening for mental disorders among afghan immigrants residing in Iran. Andishe Va Raftar. 2005;11(3):270-7.

28. Pollack CE, von dem Knesebeck O. Social capital and health among the aged: comparisons between the United States and Germany. Health Place. 2004;10(4):383-91.

29. Seyedan F, Abdolsamadi M. Relation Between Social Wealth and Mental Health of Men and Women. Res Sci Season J. 2012;11(42):229-54.

30. Shabani B, Farahani G, Jafari A. Investigation on Relation Between Organizational Commitment and Job Satisfaction in Physical Education Teachers of Hamadan Provinve. Psychol Manage Res Sport. 2011;8:33-42.

31. Goodarzi MA, Moieni Roodbali Z. The relationship between coping styles and mental health in Sepidan's high school students. Daneshvar. 2006;1(19):23-32.

32. Garousifarshi M, Mani A. Evaluating Mental Health Situation of Tabriz Oil Refinery Company Staff. J Behav. 2004;11(4):61-73. 